\title{
Improvement in diagnostic performance of the revised total testosterone measuring system in Japanese women with polycystic ovary syndrome
}

\author{
Hirobumi Niki, Toshiya Matsuzaki, Riyo Kinouchi, Takeshi Iwasa, Takako Kawami, \\ Takeshi Kato, Akira Kuwahara, and Minoru Irahara \\ Department of Obstetrics and Gynecology, Institute of Health Biosciences, the University of Tokushima \\ Graduate School
}

\begin{abstract}
Hyperandrogenemia has become an important factor in the diagnosis of polycystic ovary syndrome (PCOS), in Japan as well as Western countries, since the Japanese PCOS diagnostic criteria were revised in 2007. The revised electrochemiluminescence immunoassay (ECLIA) reagent for total testosterone (T) (ECLusys TESTO II ; New T assay), which has lower cross-reactivity with DHEA-S than the previous reagent (ECLusys TESTO I ; Old T assay), has recently been developed. We studied the improvement between New and Old $T$ assays in regards to the diagnostic performance of serum $T$ for patients with PCOS. Serum $T$ levels were measured in both normal women (Control, $n=92)$ and PCOS patients $(n=86)$. The rate of elevated $T$ using each kit was significantly higher in the PCOS group than in the Control group, and significantly higher using New $T$ assay $(38 / 86,44.2 \%)$ compared with Old $T$ assay $(26 / 86,30.2 \%)$. A significant correlation was found between $T$ level and body mass index, but not LH level. Furthermore, higher detection rates of hormonal abnormalities were seen in PCOS patients using combined measurement of both $T$ and LH (63/80) compared with single measurement of either $T(37 / 80)$ or LH (36/80). Therefore, the serum $T$ assay is essential for the diagnosis of PCOS, and New $T$ assay combined with the LH assay may improve the diagnostic process for PCOS. J. Med. Invest. 61 : 65-71, February, 2014
\end{abstract}

Keywords : PCOS, testosterone, diagnosis, LH, assay

\section{INTRODUCTION}

Polycystic ovary syndrome (PCOS) is a common ovulatory disorder in women of reproductive age, with a reported prevalence of $6-10 \%(1,2)$. PCOS is a syndrome of ovarian dysfunction, and its cardinal

Received for publication November 11, 2013 ; accepted November 25, 2013.

Address correspondence and reprint requests to Toshiya Matsuzaki, Department of Obstetrics and Gynecology, Institute of Health Biosciences, the University of Tokushima Graduate School, 3-18-15 Kuramoto-cho, Tokushima 770-8503, Japan and Fax : +81-88-631-2630. features are hyperandrogenism and polycystic ovary morphology. Other common features are insulin resistance, obesity, and elevated level of serum luteinizing hormone (LH).

The 2003 Rotterdam PCOS Consensus Workshop Group, sponsored by the European Society of Human Reproduction and Embryology (ESHRE)/American Society for Reproductive Medicine (ASRM), stipulates that, in order to fit the definition of PCOS, two or three out of the following criteria must be met : chronic anovulation ; clinical and/or biochemical evidence of hyperandrogenism ; and polycystic ovaries 
(3). These criteria have been widely accepted. On the other hand, clinical and biochemical hyperandrogenism is less prevalent in Japanese patients than in the Western population, and elevated LH levels are more common in Japanese patients with PCOS (4-6). The previous PCOS criteria of the Japanese Society of Obstetrics and Gynecology (JSOG, 1993) stipulate the presence of all three of the following factors : chronic anovulation; high LH level; and presence of polycystic ovaries (PCO) (4). Hyperandrogenemia was included only as a referential factor in these criteria because assessment of serum androgen in women has been difficult ; however, the revised PCOS criteria presented by JSOG in 2007 (Table 1) require the presence of hyperandrogenemia or elevated LH with normal serum follicle-stimulating hormone (FSH) for a diagnosis of PCOS, as well as menstrual dysfunction and polycystic ovary morphology. Therefore, assessment of serum androgen has become more important than ever.

Total testosterone $(\mathrm{T})$, one of the various androgens in the blood, is often measured in patients with PCOS. The problem is that T assay systems demonstrate inter-kit variability, especially in lower concentrations, and this is important for the diagnosis of hyperandrogenemia in women $(7,8)$. Recently, one of the major T assay systems, ECLusys TESTO I (Old T assay) was revised to become ECLusys TESTO II (New T assay) (Roche Diagnostics K.K., Tokyo, Japan). In order to reduce the nonspecific reaction in the immune reaction, these reagents immobilize the immune complex by adding streptavidincoated magnetic microparticles. The measurement principle of the reagents adopts the electrochemiluminescence immune assay (ECLIA). The ECLIA applies the principle that applying voltage to ruthenium fluorescent antibody or to ruthenium in the ruthenium fluorescent antibody can produce consecutive stable light emission of that reagent.

Furthermore, because the change of primary antibody improved the specificity for T, New T assay has lower cross-reactivity than Old T assay with dehydroepiandrosterone-sulfate (DHEA-S) and several other hormones (9).

In this study, we used both New and Old T assays to measure the subjects of normal cyclic women and PCOS patients and evaluated both the improvement in the detection rate of high testosterone level in PCOS and the benefit of the new assay combined with $\mathrm{LH}$ in the diagnosis of PCOS.

\section{MATERIALS AND METHODS}

\section{Subjects}

Ninety-two normal cyclic women (Control group) and Eighty-six patients with ovulatory dysfunction with PCOS (PCOS group) were enrolled in this study (Table 2). The Control group consisted of euthyroid women with normal serum levels of prolactin and thyroid-stimulating hormone (TSH) who had ultrasonically normal ovaries and regular menstrual cycles (25-38 days in length) with evidence of ovulation (mid-luteal phase with serum progesterone level $>10 \mathrm{ng} / \mathrm{ml}$ ).

The PCOS patients were diagnosed using the

Table 1 Diagnostic Criteria of Polycystic Ovary Syndrome by JSOG

\section{Menstrual disorder}

2. Polycystic ovary morphology

3. Hyperandrogenemia or elevated serum LH with normal serum FSH

1) Menstrual disorder means amenorrhea, oligomenorrhea or anovulatory cycle.

2) Polycystic ovary morphology means to have many small follicles by transvaginal ultrasonography, at least one ovary must have 10 follicles or more with their diameter $2-9 \mathrm{~mm}$.

3) Endocrinological inspection should be done after confirming there is no follicle with its diameter $1 \mathrm{~cm}$ or more, having no ovulatory drugs or female sex hormones. The lower detection rate of elevated serum LH should be noted within 10 days from withdrawal bleeding or menstruation.

4) Hyperandrogenemia means elevated serum total testosterone, free testosterone or androstendione.

5) Elevated serum $\mathrm{LH}$ is defined as higher level than normal average $+1 \times \mathrm{SD}(\mathrm{LH} \geqq 7 \mathrm{mIU} / \mathrm{ml}$ in Spac-S measuring system), and serum $\mathrm{LH}$ is higher than serum FSH(LH/FSH ratio $\geqq 1$ in Spac-S measuring system).

Higher LH referring to FSH without LH elevation could be approved in obesity cases(BMI is 25 or more ).

Relationship of each measuring system with Spac-S should be considered in the decision.

6) Exclusion of Cushing syndrome, adrenal enzyme disorder and recovery phase of amenorrhea due to weight loss should be done.

JSOG ; Japan Society of Obstetric and Gynecology (10)

Translated by the authors for original reference in Japanese 
PCOS diagnostic criteria of JSOG 2007, as described above (Table 1) (10), and all of them also met the criteria of Rotterdam criteria 2003 (3).

This study was approved by the institutional Ethics Committee of the University of Tokushima School of Medicine, and was conducted in accordance with the ethical standards of the Committee. Written informed consent was obtained from all patients.

Table 2 Age and BMI of the study groups

\begin{tabular}{ccc}
\hline & Control & PCOS \\
\hline $\mathrm{n}$ & 92 & 86 \\
Age & $33.0 \pm 4.5$ & $29.3 \pm 5.5^{\star}$ \\
BMI & $21.3 \pm 3.0$ & $25.2 \pm 7.5^{\star \star}$ \\
\hline
\end{tabular}

${ }^{*}: \mathrm{p}<0.05$ v.s. Control

${ }^{* *}: \mathrm{p}<0.01$ v.s. Control

\section{Blood sampling}

Serum samples were collected in the mid-follicular phase (day 7 to 9 of the menstrual cycle) in the Control group. Sampling was not timed to the menstrual cycle in the PCOS group because all patients were oligomenorrheic or amenorrheic; however, sampling was performed if no follicle more than $10 \mathrm{~mm}$ in diameter was seen on transvaginal ultrasonography on the scheduled day of blood sampling.

\section{Hormone assays}

All samples were assayed for T levels using Old and New T assays. To reduce the nonspecific reaction in the immune reaction, these reagents immobilize the immune complex by adding streptavidincoated magnetic microparticles. An electrochemiluminescence immunoassay (ECLIA) reagent kit was used for reference detection of T levels. ECLIA is carried out based on the concept that voltage applied to ruthenium fluorescent antibody or ruthenium in the ruthenium fluorescent antibody can produce consecutive stable light emission to that reagent.

New $\mathrm{T}$ assay, the revised ECLIA reagent for $\mathrm{T}$, has lower cross-reactivity than Old T assay with DHEA-S and other several hormones. The change of primary antibody has improved the specificity for the T assay.

The normal range of serum $T$ was defined as the mean value $\pm 1.96 \mathrm{SD}$ of the serum T level in normal cyclic women. Therefore, the proportion of women whose serum level of $T$ exceeds normal upper limit would be $2.5 \%$.
Serum LH levels were measured by the immunoradiometric assay (IRMA) using the SPAC-S LH kit (TFB, Inc., Tokyo, Japan) in 80 patients of the PCOS group whose extra serum was adequate for the LH assay.

\section{Outcome measures}

The following outcome measures were studied : 1) serum $T$ levels of the two groups using Old and New T assays ; 2) distribution of serum T levels of the two groups using Old and New T assays ; 3) relative numbers of patients with elevated serum T levels in the PCOS group using Old or New T assay ; 4) correlation between serum $T$ levels by New $\mathrm{T}$ assay and body mass index (BMI) in the PCOS group ; and 5) correlation between serum $T$ levels by New T assay and serum LH levels in the PCOS group.

\section{Statistical analysis}

Data are expressed as the mean \pm SD. Analysis of differences in mean values were determined using the $t$-test. Correlations between variables were determined using Spearman's rank order analysis. The Chi-square test was used for elevated $\mathrm{T}$ distribution between the groups or between the two assays. $P$ values $<0.01$ were considered statistically significant. The statistical software program JMP, version 6.0.0 (SAS Institute Japan Ltd., Tokyo, Japan) was used for analysis.

\section{RESULTS}

Serum T levels by Old T assay were $0.34 \pm 0.14$ $\mathrm{ng} / \mathrm{ml}($ mean $\pm \mathrm{SD})$ and $0.57 \pm 0.29 \mathrm{ng} / \mathrm{ml}$ in the Control and the PCOS groups, respectively (Fig. 1). Serum T levels by New T assay were $0.25 \pm 0.10$ $\mathrm{ng} / \mathrm{ml}$ and $0.46 \pm 0.20 \mathrm{ng} / \mathrm{ml}$ in the Control and the PCOS groups, respectively. Serum T levels were significantly higher in the PCOS group than in the Control group, in both Old and New T assays $(p<$ 0.0001).

The distribution of serum T levels in the two groups overlapped ; however, the serum $\mathrm{T}$ levels of the PCOS group were distributed in a higher range (Fig. 2). This distribution pattern seemed more apparent in New T assay than in Old T assay.

The number of PCOS patients whose serum T levels exceeded the upper limit of normal range was significantly greater in New T assay $(38 / 86,44.2 \%)$ than in Old T assay $(26 / 86,30.2 \%)(\mathrm{p}<0.05)$ (Table 3$)$. 
The number of patients whose serum $T$ levels exceeded the upper limit of normal range were, of

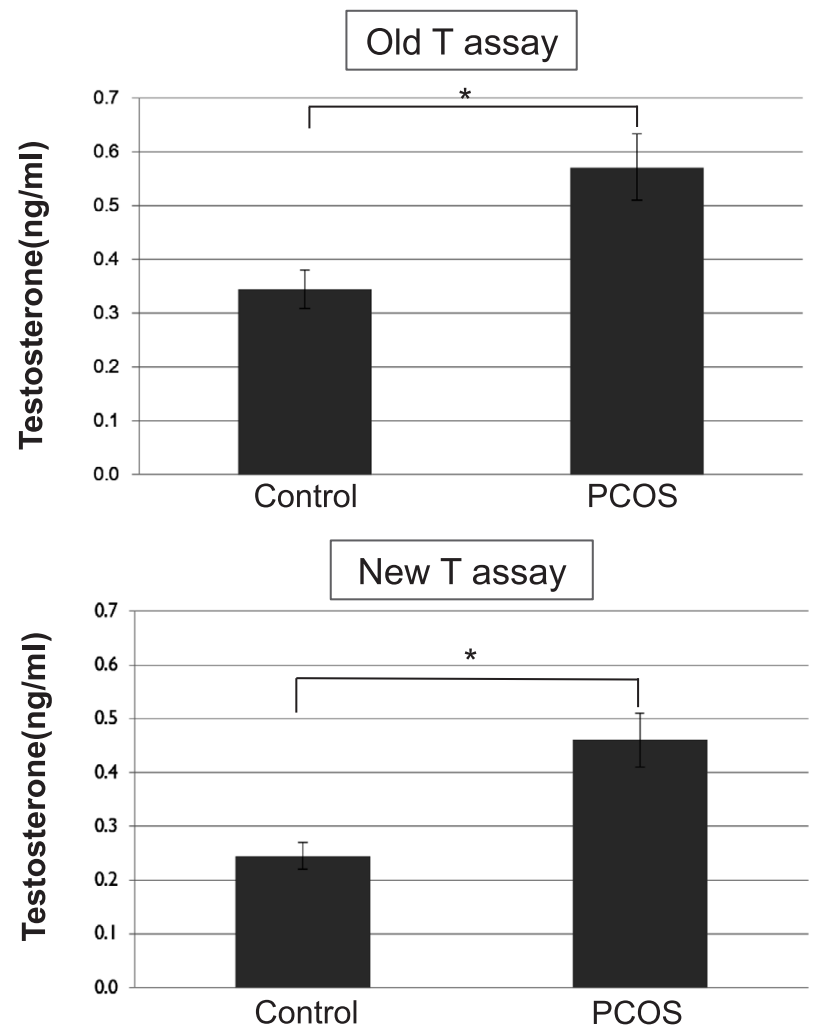

Fig. 1 Serum testosterone level was significantly higher in the PCOS group than in the Control group, by both Old T assay (upper panel) and New T assay (lower panel). ${ }^{*}: \mathrm{p}<0.0001$ vs. Control. Horizontal bar=SD.

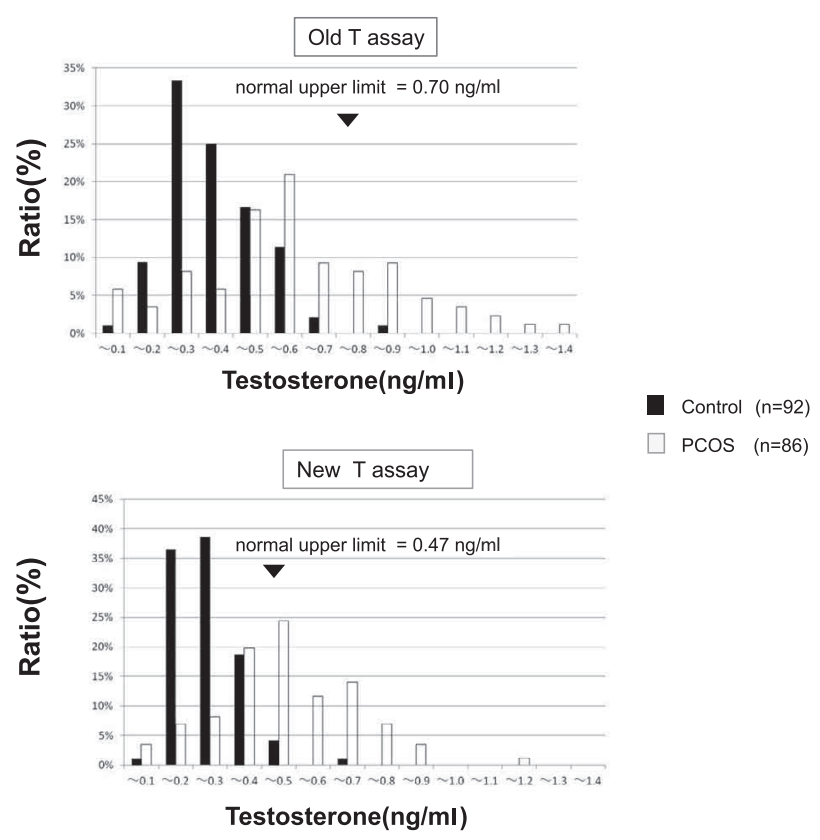

Fig. 2 Distribution of serum testosterone levels in the Control group ( $\square, n=92)$ and PCOS group $(\square, n=86)$ in the two assays. Upper limits of the normal range in normal cyclic women are $0.70 \mathrm{ng} / \mathrm{ml}$ in Old T assay and $0.47 \mathrm{ng} / \mathrm{ml}$ in New T assay. course, greater in the PCOS group than in the Control group, in both Old and New T assays $(\mathrm{p}<0.05)$.

Fig. 3 shows the distribution of serum T levels between Old and New T assays in the Control and PCOS groups. New $T$ assay revealed elevated $T$ in 38 PCOS patients ; Old T assay revealed elevated $\mathrm{T}$ in only 26 PCOS patients. Twelve PCOS patients were proved to have elevated T only by New T assay.

Serum T level in PCOS patients by New T assay showed significant correlation with BMI (Fig. 4). On the other hand, serum T level in PCOS patients by New T assay showed no correlation with serum LH level (Fig. 5). Furthermore, combined measurement of both $\mathrm{T}$ and $\mathrm{LH}$ showed a higher detection rate of hormonal abnormality in the PCOS group (54/80), compared with single measurement of $\mathrm{T}(37 / 80)$ or LH $(36 / 80)$.

Table 3 Subjects with elevated serum testosterone(T) level were dominant in the PCOS group and elevated T was more evident in New T assay than in Old T assay

\begin{tabular}{ccc}
\hline & $\begin{array}{c}\text { Old T assay } \\
\text { Control }\end{array}$ & PCOS \\
\hline $\begin{array}{c}\text { Normal T } \\
(<0.70 \mathrm{ng} / \mathrm{ml})\end{array}$ & 91 & 60 \\
$\begin{array}{c}\text { Elevated T } \\
(\geqq 0.70 \mathrm{ng} / \mathrm{ml})\end{array}$ & 1 & $26^{\mathrm{a}}$ \\
\hline & New T assay & \\
\hline & Control & PCOS \\
\hline $\begin{array}{c}\text { Normal T } \\
(<0.47 \mathrm{ng} / \mathrm{ml}) \\
\text { Elevated T } \\
(\geqq 0.47 \mathrm{ng} / \mathrm{ml})\end{array}$ & 91 & 48 \\
\hline
\end{tabular}

note. Significant greater number by Chi-square test $(\mathrm{a}, \mathrm{b})$ $\mathrm{a}: \mathrm{p}<0.05$, v.s. the Control group in each assay. $\mathrm{b}: \mathrm{p}<0.05$, v.s. Old T assay of the PCOS group.

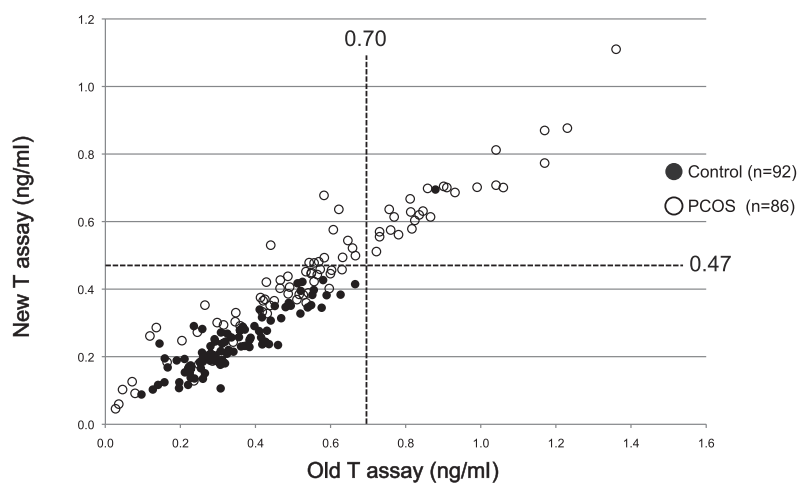

Fig. 3 Distribution of serum testosterone levels between Old and New T assays in the Control group $(\bullet, n=92)$ and PCOS group $(\circ, \mathrm{n}=86)$. Dashed lines mean the upper limits of the normal range in normal cyclic women : $0.70 \mathrm{ng} / \mathrm{ml}$ in Old T assay and $0.47 \mathrm{ng} / \mathrm{ml}$ in New T assay. 


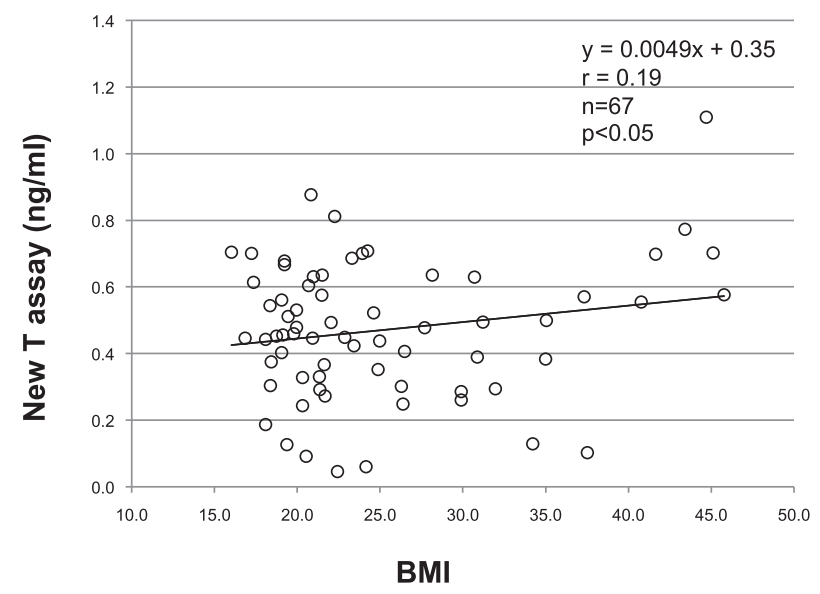

Fig. 4 Relationship between body mass index (BMI) and serum testosterone level measured by New T assay. A correlation was found between BMI and serum testosterone level.

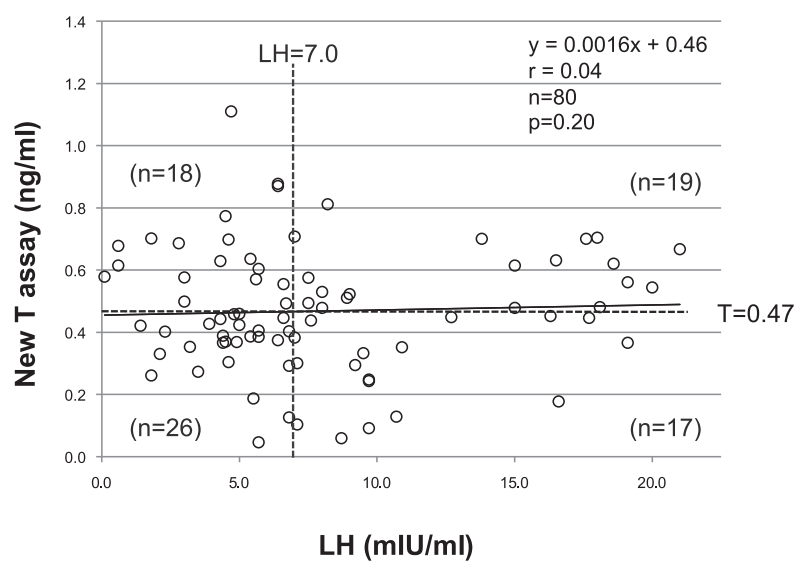

Fig. 5 Relationship between serum LH and serum testosterone level measured by New T assay. No correlation was found between serum LH level and serum testosterone level. Dashed lines mean cut-off value for the diagnosis of PCOS : $7.0 \mathrm{IU} / \mathrm{ml}$ for $\mathrm{LH}$, which is mean $+1 \mathrm{SD}$ in normal cyclic women and $0.47 \mathrm{ng} / \mathrm{ml}$ for testosterone, which is mean $+1.96 \mathrm{SD}$ in normal cyclic women. Number of patients in the four areas divided by two dashed lines is shown in parentheses.

\section{DISCUSSION}

Hyperandrogenemia is the typical feature of PCOS, and is listed as one of the essential elements for the diagnosis of PCOS, not only in Western countries (3), but also in Japan (10). However, accurate measurement of the serum T level, which is a major indicator of androgen synthesis in the gonads, has been difficult in women because their serum level is much lower than that of men ; therefore, the cross-reaction with other steroid hormones severely interferes with the precise diagnosis of hyperandrogenic diseases in women. As for serum free testosterone(FT), which should have an important role in assessment of the hyperandrogenemia/hyperandrogenism, the assay system has shown low accuracy in women range as seen in T assay. Serum FT was not so frequently measured in patients without hirsutism, and limited data showed lower ability of FT to distinguish PCOS and other ovulatory disorders although elevated FT is highly detected in these patients (10). Recently, ECLusys TESTO I (Old T assay), one of the major assay systems for $\mathrm{T}$, has been revised to become TESTO II (New T assay), mainly by reducing the cross-reactivity with DHEA-S of the first antibody.

The present study assessed the efficacy of this revision in the diagnosis of PCOS. We prepared adequate number of serum samples for the present analysis of 86 PCOS patients who were previously diagnosed with PCOS and 92 normal cyclic women as a Control group in order to measure T levels using both Old and New T assays. We additionally evaluated the combined hormonal assessment of $T$ and LH in the diagnosis of PCOS. As a result, both Old and New T assays revealed higher T levels and an extremely higher proportion of patients with elevated T in the PCOS group than in the Control group. Furthermore, the proportion of patients with elevated T in the PCOS group was significantly higher in New T assay than in Old T assay, demonstrating the improvement in the diagnosis of PCOS in this revision of the assay system clearly. Old T assay detected elevated T in $30.2 \%$ of PCOS patients ; however, New T assay detected it in as many as $44.2 \%$ of the same patient population. No patients showed elevated T only in Old T assay. Detecting elevated T used to be difficult; in a 2007 report (10), only $14.3 \%$ of PCOS patients were reported to have elevated $\mathrm{T}$ in a Japanese survey from sum of data using various $\mathrm{T}$ assay systems. The present result of $44.2 \%$, detectable as elevated T in PCOS patients, is higher than ever reported using the previous assay systems in Japan (11). This remarkable advance in $T$ assay encourages the precise diagnosis of PCOS in Japanese patients.

As for the measured value of T, New T assay shows an almost $40 \%$ decrease compared with the Old T assay in female samples, although almost the same value is noted in male samples (12). Therefore, when we compare the measured value between these assays with respect to patients with female reproductive disorders, we must take note of this major reduction in the values. In the present study, New T assay showed lower values than Old T assay in both Control and PCOS groups. The reason for 
this reduction in measured $\mathrm{T}$ values is well explained by the low cross-reaction to DHEA-S in the New T assay. Some reports have demonstrated T levels relatively higher than indicated by clinical symptoms $(13,14)$. In basic studies, cross-reaction to DHEA-S was reported as $<0.003 \%$ in New T assay and $0.01 \%$ in Old T assay $(15,16)$. Cross-reaction to DHEA-S in New T assay would therefore be lower than $30 \%$ of that in Old T assay. In Old T assay, $1 \mu \mathrm{g} / \mathrm{dl}$ of DHEA-S would raise the T value by $0.0008155 \mathrm{ng} / \mathrm{ml}$ (9). The difference in the serum DHEA-S level between the sexes was not so great, although $\mathrm{T}$ levels were 10 times higher in males than in females. When the DHEA-S serum level is $300 \mu \mathrm{g} / \mathrm{dl}$ in males and $200 \mu \mathrm{g} / \mathrm{dl}$ in females as around each mode of the normal range, $0.245 \mathrm{ng} /$ $\mathrm{ml}$ in males and $0.163 \mathrm{ng} / \mathrm{ml}$ in females would be measured as $\mathrm{T}$ due to cross-reaction. In considering the serum $T$ level, the calculated value of the crossreaction is small in the male $T$ level, however, it is seriously large in the female $\mathrm{T}$ level. Therefore, Old $\mathrm{T}$ assay was largely influenced by serum DHEA-S and New $T$ assay largely reduced this influence, resulting in a $40 \%$ reduction in the measured values only in females. For the same reason, a histogram of the serum T levels of the Control and PCOS groups in New T assay was apparently less overlapped compared with Old T assay or other assay systems (11) ; therefore, an elevated T level by New T assay is higher than $\mathrm{T}$ levels determined by previous assay systems.

Androgen synthesis in the theca cells of the ovaries is enhanced by hyperinsulinemia from insulin resistance in PCOS patients, and insulin resistance is enhanced by obesity (5). Therefore, serum T levels correlated positively with BMI. On the other hand, we demonstrated that serum $\mathrm{T}$ level showed no correlation with serum LH level. T and LH are important endocrinological disorders of PCOS which do not correlate with each other. Therefore, measurement of both these two hormones would increase the detection rate of hormonal abnormality in PCOS patients.

Endocrinological assessment of LH or T in patients with PCOS does have some problems. Regarding evaluation of T levels, low sensitivity has been a major problem ; however, this has been improved by a revision of assay systems. On the other hand, problems in LH assessment have included frequent fluctuation of serum levels by pulsatile secretion at about 60-min intervals in PCOS, which causes a 2 -mIU difference according to the timing of blood sampling. Endogenous or exogenous estrogen and progesterone also influence the LH level. As a result, the reproducibility of the serum LH level is low $(10,17)$. Therefore, detection of elevated LH is sometimes difficult and, in fact, some patients (26/ 80 ) in the present study did not show elevated $\mathrm{T}$ or $\mathrm{LH}$, even though they were diagnosed with PCOS by at least one hormonal examination previously. In the diagnostic criteria for PCOS in Japan (10), a required endocrinological factor is elevated androgen or LH. T and LH are thought to be complementary to each other. In that report (10), combined $\mathrm{T}$ or other androgens and the $\mathrm{LH}$ assay raised the detection rate of endocrinological disorders. However, the $\mathrm{T}$ assay provided little contribution to the combined assay (10) because of the low potential of the T assay in those days. In the present study, New T assay showed an extremely higher potential for the detection of elevated $\mathrm{T}$ more than ever, giving a real chance for success in the combined measurement of T and LH. In the present study, patients with elevated $\mathrm{LH}$ without $\mathrm{T}$ were seen in the proportion of $21.3 \%(17 / 80)$, and patients with elevated $T$ without LH constituted $22.5 \%$ (18/80). Patients with both T and LH elevation made up only $23.8 \%(19 / 80)$. The combined measurement of T and LH could detect endocrinological disorder in $67.5 \%(54 / 80)$ of the PCOS patients. New T assay combined with the LH assay seemed effective in the diagnosis of PCOS.

In conclusion, we demonstrated an improvement in the detection rate of elevated T in PCOS using the same patient population using both previous and revised $\mathrm{T}$ assay systems simultaneously, and we additionally showed that the $T$ measurement by revised T assay combined with LH measurement markedly improved the diagnostic process for PCOS.

\section{CONFLICT OF INTEREST}

The authors declare that there are no conflicts of interest that would prejudice the impartiality of this scientific work.

\section{ACKNOWLEDGMENT}

This work was supported by JSPS KAKENHI Grant Number 24592472, 24592473 and Seiikuiryoukenkyukaihatsuhi 2013. 


\section{REFERENCES}

1. Knochenhauer ES, Key TJ, Kahsar-Miller M, Waggoner W, Boots LR, Azziz R : Prevalence of the polycystic ovary syndrome in unselected black and white women of the southeastern United States : a prospective study. J Clin Endocrinol Metab 83 : 3078-3082, 1998

2. Asunción M, Calvo RM, San Millán JL, Sancho J, Avila S, Escobar Morreale HF : A prospective study of the prevalence of the polycystic ovary syndrome in unselected Caucasian women from Spain. J Clin Endocrinol Metab 85 : 2434-2438, 2000

3. The Rotterdam ESHRE/ASRM-sponsored PCOS Consensus Workshop Group : Revised 2003 consensus on diagnostic criteria and longterm health risks related to polycystic ovary syndrome. Fertil Steril $81: 19-25,2004$

4. Sugimoto O, Aono T, Kuwabara S, Taketani Y, Irahara $\mathrm{M}$ : The Committee for Reproductive and Endocrine in Japan Society of Obstetrics and Gynecology. Annual report (1991-1992) for the determination of diagnostic criteria for polycystic ovary syndrome. Acta Obstet Gynaecol Jpn 45 : 1359-1367, 1993 [In Japanese]

5. Carmina E, Koyama T, Chang L, Stanczyk FZ, Lobo RA : Does ethnicity influence the prevalence of adrenal hyperandrogenism and insulin resistance in polycystic ovary syndrome? Am J Obstet Gynecol 167 : 1807-1812, 1992

6. Goldzieher JW : Polycystic ovarian disease. Fertil Steril 35 : 371-394, 1981

7. Boots LR, Potter S, Potter HD, Azziz R : Measurement of total serum testosterone levels using commercially available kits : high degree of between-kit variability. Fertil Steril 69 : 286292, 1998

8. Stanczyk FZ, Cho MM, Endores DB, Morrison JL, Patel S, Paulson RJ : Limitations of direct estradiol and testosterone immunoassay kits. Steroids 68 : 1173-1178, 2003
9. Middle JG : Dehydroepiandrostenedione sulphate interferes in many direct immunoassays for testosterone. Ann Clin Biochem 44 : 173177, 2007

10. Mizunuma H, Irahara M, Kugu K, Takahashi K, Douchi T, Fujii S, Matsuzaki T : The Committee for Reproductive and Endocrine in Japan Society of Obstetrics and Gynecology : Annual Report (2005-2006) of the Revised Diagnostic Criteria for Polycystic Ovary Syndrome. Acta Obstet Gynaecol Jpn 59 : 868-886, 2007 [In Japanese]

11. Iwasa T, Matsuzaki T, Minakuchi M, Tanaka N, Shimizu F, Hirata Y, Kuwahara A, Yasui T, Maegawa M, Irahara M : Diagnostic performance of serum total testosterone for Japanese patients with polycystic ovary syndrome. Endocr J 54 : 233-238, 2007

12. Kinouchi R, Matsuzaki T, Iwasa T, Mimuro T, Irahara $\mathrm{M}$ : Setting of normal range of serum total testosterone, $\mathrm{LH}$ and FSH in ECLusys measuring system. Igaku Yakugaku 64 : 87-93, 2010 [In Japanese]

13. Herald DA, Fitzgerald RL : Immunoassays for testosterone in women : better than a guess? Clin Chem 49 : 1250-1251, 2003

14. Taieb J, Mathian B, Millot F, Patricot MC, Mathieu E, Queyrel N, Lacroix I, SommaDelpero C, Boudou P : Testosterone measured by 10 immunoassays and by isotope-dilution gas chromatography-mass spectrometry in sera from 116 men, women and children. Clin Chem $49: 1381-1395,2003$

15. ECLusys TESTO I attached document (Roche Diagnostics K.K., Japan)

16. ECLusys TESTO II attached document (Roche Diagnostics K.K., Japan)

17. Iwasa T, Matsuzaki T, Murakami M, Shimizu F, Kuwahara A, Yasui T, Irahara M : Reproducibility of luteinizing hormone hypersecretion in different phases of the menstrual cycle in polycystic ovary syndrome. J Obstet Gynaecol Res 35 : 514-519, 2009 